\title{
Finding a needle in a haystack: Endoscopic ultrasound-guided fine-needle aspiration for solid pancreatic masses in the setting of chronic pancreatitis
}

\author{
Chencheng Xie ${ }^{a}$, Kimberlee Bohy ${ }^{b}$, Mohamed A. Abdallaha, Bhaveshkumar Patelc, Morgan E. Nelsond, \\ Jonathan Bleeker ${ }^{\mathrm{e}}$, Ryan Askeland ${ }^{\mathrm{b}}$, Ammar Abdullaha, Khalil Aloreidia, Rabia Kiania, Muslim Atiq ${ }^{\mathrm{c}}$
}

University of South Dakota, Sioux Falls, SD, USA

\section{Abstract}

\section{Introduction}

Endoscopic ultrasound-guided fine-needle aspiration (EUS-FNA) is routinely used for the evaluation and tissue

${ }^{\text {aDepartment }}$ of Internal Medicine (Chencheng Xie, Mohamed A. Abdallah, Ammar Abdullah, Khalil Aloreidi, Rabia Kiani); ${ }^{\text {DDepartment of }}$ Pathology (Kimberlee Bohy, Ryan Askeland); ' Division of Gastroenterology and Hepatology (Bhaveshkumar Patel, Muslim Atiq); ${ }^{\mathrm{d} D e p a r t m e n t ~ o f ~}$

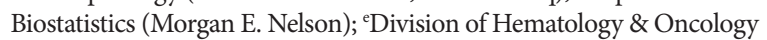
(Jonathan Bleeker), University of South Dakota, Sioux Falls, SD, USA

\section{Conflict of Interest: None}

Correspondence to: Muslim Atiq, MD, Sanford Health, Division of Gastroenterology and Hepatology, University of South Dakota, Sioux Falls, SD, USA, e-mail: Muslim.Atiq@Sanfordhealth.org

Received 9 February 2020; accepted 5 March 2020; published online 10 May 2020

DOI: https://doi.org/10.20524/aog.2020.0484 acquisition of pancreatic lesions [1]. EUS-FNA has excellent diagnostic accuracy (83-95\%) [2-6]. However, in the setting of chronic pancreatitis (CP) it has been criticized for its relatively low negative predictive value (NPV) and high false-negative (FN) rate [7-13]. Studies have shown that the overall diagnostic sensitivity of EUS-FNA in the setting of CP is approximately 54-74\%, compared to $89-96 \%$ in patients without CP [8-10].

From a clinical standpoint, pancreatic malignancy and CP share several common features, posing a diagnostic dilemma. First, both $\mathrm{CP}$ and pancreatic adenocarcinoma (pCA) share common risk factors, such as smoking and alcohol consumption. Second, CP itself is a known risk factor for pCA. It has been reported that $20-35 \%$ of patients undergoing EUS-FNA in the evaluation of pancreatic lesions exhibit CP features [10]. Third, patients with CP and pancreatic cancer can manifest similar clinical features at presentation, including jaundice, abdominal pain, weight loss, and new-onset diabetes.

On EUS sonographic evaluation, certain findings can pose challenges to adequate imaging. For instance, confluent 
lobularity without honeycombing could mimic mass lesions, calcified stones could mask underlying lesions, and collateral vasculature poses challenges to the safety of FNA [7]. Therefore, underlying CP might lower the accuracy of the morphological interpretation of pancreatic mass.

From the cytological perspective, it has been postulated that the lower diagnostic yield of EUS-FNA includes inadequate sampling and off-target biopsying [7]. Furthermore, the presence of $\mathrm{CP}$ could make cytological interpretation of the aspirate more challenging. First, $\mathrm{CP}$ aspirates might depict atypical cytological features manifested as large nuclei, degenerative vacuoles, and occasional mitoses, which may mimic malignancy and can be difficult to distinguish from adenocarcinoma. Second, well-differentiated adenocarcinomas without hyperchromasia display modestly elevated nuclear-tocytoplasmic ratios and minimal architectural disorder [1,7]. Additionally, adenocarcinoma typically coexists with desmoplasia and inflammatory infiltrates, which may result in inadequate sampling [1,7].

Regardless of the specific circumstances of an individual case, the missed diagnosis of a malignant lesion of the pancreas often results in further redundant testing, such as crosssectional imaging or positron-emission tomography imaging, and in some cases, repeat EUS procedures. Most importantly, a missed diagnosis causes a delay that could have significant repercussions in regard to timely treatment.

Conversely, overzealous EUS-FNA interpretation can generate false-positive (FP) results. In one report, investigators noted a FP rate of $2.2 \%$ for pancreatic FNA [14]. This would invariably result in subjecting patients to unnecessarily aggressive treatment regimens, including chemotherapy and/or surgery.

This study aimed to evaluate the diagnostic yield of EUSFNA for solid pancreatic lesions in the presence or absence of CP. Although this has been studied before, most of the literature on this topic comes from established academic centers. Our data brings in a unique perspective from a community-based regional referral center, where patients are mostly seen without a prior endosonographic exam.

\section{Patients and methods}

This study was a single-center retrospective analysis of EUS-FNA for suspected pancreatic neoplasms at Sanford USD Medical Center. We identified patients who underwent EUSFNA at our institution between July 15, 2011 and November 30, 2017. Details regarding demographic data, clinical characteristics at presentation, radiological findings, EUS findings, cytopathology, and clinical course were recorded.

Patients who met the following criteria were included in the study: 1) endoscopic retrograde cholangiopancreatography confirmed biliary stricture; and 2) abnormal findings on ultrasonography, computed tomography, and/or magnetic resonance imaging suggestive of pancreatic masses, intrahepatic or extrahepatic bile duct dilation, or pancreatic duct dilation. Patients who had cystic lesions with the associated solid mass/lesion were included in the study. Patients with imaging studies or EUS suggestive of cystic neoplasms and benign or inflammatory cysts were excluded.

\section{EUS exam}

All patients underwent an EUS examination with a curvilinear echoendoscope. FNA was performed for any identified or suspected pancreatic lesions. EUS reports were reviewed to document findings relative to $\mathrm{CP}$, based on the Rosemont criteria and endosonographic impression, categorized as "consistent with," "suggestive of," or "indeterminate for" CP [15-18]. The pancreatic parenchymal features recorded, were: 1) hyperechoic foci with stranding/shadowing (Major A); 2) lobularity with honeycombing (Major B); 3) hyperechoic foci without shadowing/shadowing (Minor); 4) lobularity without honeycombing (Minor); 5) stranding/hyperechoic strands (Minor); and 6) cysts (Minor). The 5 ductal features included: 1) main pancreatic duct calculi (Major A); 2) irregular main pancreatic duct contour (Minor); 3) dilated side branches (Minor); 4) main pancreatic duct dilatation (Minor); and 5) hyperechoic duct margin (Minor). Based on the Rosemont criteria, the interpretation of pancreas texture can be classified as "consistent with CP" (1 Major A feature with $\geq 3$ Minor features, 1 Major A feature and 1 Major B feature, or 2 Major A features), "suggestive of CP" (1 Major A feature with $<3$ Minor features, 1 Major B feature with $\geq 3$ Minor features, or $\geq 5$ Minor features), "indeterminate for CP" (3 or 4 Minor features with no Major features, or Major B feature alone or with $<3$ Minor features), and "normal" (<3 Minor features, no Major features) [16-19].

The endoscopist also documented intraoperative CP impressions [15]. In most cases, the interpretation of CP was consistent between the Rosemont criteria and the endoscopist's clinical impression. A discrepancy was noted in $18 / 234$ (7.7\%), and we chose the operator's clinical impression as the final interpretation. Patients were categorized as "consistent with," "suggestive of," or "indeterminate for" CP in the final interpretation. In this analysis, the "consistent with" and "suggestive of" CP patients were categorized as having a diagnosis of $\mathrm{CP}$, whereas "indeterminate" and "normal" features were categorized as patients without CP.

\section{Cytology and interpretation}

Rapid on-site evaluation (ROSE) of the specimens was performed by cytopathologists after EUS-FNA. The cytology was reported as "benign," "atypical," "suspicious/highly suspicious," or "positive/malignant" for malignancy. "Benign" or "atypical" evaluations were considered "negative" cytology. "Suspicious/highly suspicious" and "positive/malignant" evaluations were considered "positive" for malignancy.

\section{Follow up and final diagnosis}

The final diagnosis was based on definitive surgical pathologic results and clinical follow up. Lesions were 
confirmed as benign when there was no clinical or radiological progression of the disease for at least 6 months.

\section{Interpretation of final results}

The interpretation of the final results needed to take into consideration the cytology report and the definitive diagnosis. FN cases were defined as those patients whose initial cytology was suggestive of "atypical" or "benign" findings but were later found to have malignancy, either in surgical specimens or by clinical follow up. FPs were defined as those patients whose initial cytology was "suspicious/highly suspicious" or "positive" for malignancy, but malignancy could not be confirmed by surgical specimen or clinical follow up. True negatives were defined as those patients whose cytology was "atypical" or "benign," and later clinical follow up indicated benign etiology. True positives were defined as those patients whose cytology was "suspicious/highly suspicious" or "positive" for malignancy, and the final clinical outcome confirmed malignancy by surgical specimen or clinical follow up.

\section{Statistical analysis}

SAS 9.4 statistical software was used for analysis. For bivariate analysis, 2-sided $t$-tests were used for normally distributed continuous variables and reported as (mean $\pm \mathrm{SD}$ ). Wilcoxon rank-sum tests were used for skewed continuous variables and reported as [median (interquartile range, IQR)], and chisquare tests were used for categorical variables. Proc logistic in SAS was used to analyze multiple logistic regression model predictors of CP. Statistical significance was set at $\mathrm{P}<0.05$.

\section{Results}

A total of 356 consecutive EUS-FNA procedures were recorded. Eleven cases were lost to follow up; 2 cases with incomplete EUS reports and 1 case with unclear origin from the stomach or pancreas were excluded. Another 108 cases with cystic lesions were excluded from the database. Overall, 234 EUS-FNA evaluations for solid pancreatic lesions performed in 230 patients were included in this analysis.

\section{General characteristics and clinical presentation of patients}

Among the 234 EUS-FNA evaluations, 44 cases (18.8\%) had underlying CP. The age of the patients was $67.6 \pm 12.62$ years. The most common presenting symptoms in patients with solid pancreatic lesions were abdominal pain in 161 cases (69\%) and jaundice in 99 (42\%).

Patients with $\mathrm{CP}$ were relatively younger than those without $\mathrm{CP}$ (63 years vs. 68 years, $\mathrm{P}=0.0099$ ). Patients with $\mathrm{CP}$ were less likely to present with jaundice compared to those without CP (27\% vs. $46 \%, \mathrm{P}=0.025)$. However, there was no significant difference in abdominal pain between these two groups $(\mathrm{P}=0.79)$ (Table 1).

The final diagnosis was adenocarcinoma in $156(67.2 \%)$ patients, neuroendocrine tumor (NET) in 27 (11.6\%), lymphoma in $6(2.6 \%)$, metastatic malignancy in $8(3.4 \%)$, benign etiologies, including normal tissue or CP, in 35 (15\%), and 1 case of gastrointestinal stromal tumor outside of the categories mentioned above. Most of the lesions were located in the head/neck region (54\%). Patients without CP more commonly had a solid pancreatic lesion in the head/neck region compared to those with CP (57\% vs. $41 \%, \mathrm{P}<0.001)$. Patients with CP had a relatively higher rate of negative cytology $(50 \%$

Table 1 General clinical characteristics of patients with suspected solid pancreatic lesions (pancreatic mass and/or biliary or pancreatic duct strictures) in the presence or absence of chronic pancreatitis

\begin{tabular}{|c|c|c|c|c|}
\hline \multirow[t]{3}{*}{ Characteristics } & \multicolumn{2}{|c|}{ Chronic pancreatitis } & \multirow[t]{3}{*}{ P-value } & \multirow[t]{2}{*}{ Total $(\mathrm{N}=234)$} \\
\hline & No $(N=190)$ & Yes $(\mathrm{N}=44)$ & & \\
\hline & $\mathrm{N}(\%)$ or mean $\pm \mathrm{SD}$ & $\mathrm{N}(\%)$ or mean $\pm \mathrm{SD}$ & & $\mathrm{N}(\%)$ or mean $\pm \mathrm{SD}$ \\
\hline Age (years) & $68.7 \pm 11.96$ & $63.2 \pm 14.51$ & 0.0099 & $67.6 \pm 12.62$ \\
\hline $\begin{array}{l}\text { Sex } \\
\text { Female } \\
\text { Male }\end{array}$ & $\begin{array}{c}79(42 \%) \\
111(58 \%)\end{array}$ & $\begin{array}{l}14(32 \%) \\
30(68 \%)\end{array}$ & 0.2332 & $\begin{array}{c}93(40 \%) \\
141(60 \%)\end{array}$ \\
\hline $\begin{array}{l}\text { Race } \\
\text { Caucasian } \\
\text { Asian } \\
\text { African } \\
\text { Native }\end{array}$ & $\begin{array}{c}188(99 \%) \\
1(0.5 \%) \\
0(0) \\
1(0.5 \%)\end{array}$ & $\begin{array}{c}44(100 \%) \\
0(0) \\
0(0) \\
0(0)\end{array}$ & $>0.99$ & $\begin{array}{c}232(99 \%) \\
1(0.4 \%) \\
0(0) \\
1(0.4 \%)\end{array}$ \\
\hline Abdominal pain & $130(68 \%)$ & $31(70 \%)$ & 0.7931 & $161(69$ \\
\hline Jaundice & $87(46 \%)$ & $12(27 \%)$ & 0.0251 & $99(42 \%)$ \\
\hline BMI $\left(\mathrm{kg} / \mathrm{m}^{2}\right)$ & $28.0 \pm 6.40$ & $26.5 \pm 4.95$ & 0.1529 & $27.75 \pm 6.17$ \\
\hline
\end{tabular}

BMI, body mass index; $N$, number; $S D$, standard deviation 
vs. $9 \%, \mathrm{P}<0.001)$ and a lower rate of positive cytology $(45 \%$ vs. $84 \%, \mathrm{P}<0.001)$ compared to non-CP patients. More EUSFNA passes were required in the presence of $\mathrm{CP}$ compared to without $\mathrm{CP}$ [median=2 (IQR: 1.5, 4.0) vs. median=2 (IQR: 1.0, 3.0), $\mathrm{P}=0.027]$. There was no statistical difference between the 2 groups in regard to lesion size $(\mathrm{P}=0.64)$, needle gauge $(\mathrm{P}=0.12)$, or cross-imaging features $(\mathrm{P}>0.99)$ (Table 2$)$.

\section{Performance characteristics of EUS-FNA in the diagnostic evaluation of solid pancreatic lesions}

Among the 234 cases, 2 case results posed a diagnostic dilemma. In the first case, FNA cytology reported low-grade spindle cell neoplasm, but the surgical pathology confirmed malignant lymphoma. In the other case, FNA cytology reported NETs, but the surgical pathology reported metastatic clear cell renal cell carcinoma. Accordingly, these 2 cases were excluded from further analysis.

The overall diagnostic sensitivity, specificity, PPV, NPV, and accuracy of EUS-FNA in the diagnosis of malignancy (adenocarcinoma, NET, lymphoma, or metastatic lesions to the pancreas) were $92.9 \%, 97.1 \%, 99.5 \%, 70.8 \%$, and $93.5 \%$, respectively. The sensitivity of EUS-FNA for diagnosing malignancy was significantly lower in patients with $\mathrm{CP}$ compared to those without ( $80 \%$ vs. $95 \%, \mathrm{P}=0.020)$. The accuracy of EUS was also significantly lower in the setting of CP ( $86 \%$ vs. $95 \%, \mathrm{P}=0.043$ ). There were no significant differences in specificity, PPV or NPV for the detection of malignancy with or without CP (Table 3).

Table 2 EUS-FNA related features, cross imaging features, cytology, and clinical diagnosis of patients with suspected solid pancreatic lesions (pancreatic mass and/or biliary or pancreatic duct strictures) in the presence or the absence of chronic pancreatitis

\begin{tabular}{|c|c|c|c|c|}
\hline \multirow[t]{3}{*}{ Characteristics } & \multicolumn{2}{|c|}{ Chronic pancreatitis } & \multirow[t]{3}{*}{ P-value } & \multirow[t]{2}{*}{ Total $(\mathrm{N}=234)$} \\
\hline & No $(\mathrm{N}=190)$ & Yes $(\mathrm{N}=44)$ & & \\
\hline & $\mathrm{N}(\%)$ or mean $\pm \mathrm{SD}$ & $\mathrm{N}(\%)$ or mean $\pm \mathrm{SD}$ & & $\mathrm{N}(\%)$ or mean $\pm \mathrm{SD}$ \\
\hline $\begin{array}{l}\text { Mean diameter of lesions } \\
\text { (Cross-imaging) }(\mathrm{mm})\end{array}$ & $33.2 \pm 18.26$ & $31.5 \pm 19.87$ & 0.6486 & $32.9 \pm 18.5$ \\
\hline $\begin{array}{l}\text { Imaging description } \\
\text { None } \\
\text { CBD or PD dilation/stricture } \\
\text { Mass on US/CT/MRI } \\
\text { Both }\end{array}$ & $\begin{array}{c}11(6 \%) \\
20(11 \%) \\
86(45 \%) \\
73(38 \%)\end{array}$ & $\begin{array}{c}4(9 \%) \\
10(23 \%) \\
16(36 \%) \\
14(32 \%)\end{array}$ & 0.1205 & $\begin{array}{c}15(6 \%) \\
30(13 \%) \\
102(44 \%) \\
87(37 \%)\end{array}$ \\
\hline $\begin{array}{l}\text { Location of lesions (EUS) } \\
\text { None } \\
\text { Head/neck } \\
\text { Body } \\
\text { Tail } \\
\text { Others } \dagger\end{array}$ & $\begin{array}{c}8(4 \%) \\
108(57 \%) \\
31(16 \%) \\
29(15 \%) \\
14(7 \%)\end{array}$ & $\begin{array}{c}10(23 \%) \\
18(41 \%) \\
4(9 \%) \\
8(18 \%) \\
4(9 \%)\end{array}$ & 0.0007 & $\begin{array}{c}18(8 \%) \\
126(54 \%) \\
35(15 \%) \\
37(16 \%) \\
18(8 \%)\end{array}$ \\
\hline $\begin{array}{l}\text { FNA cytology } \\
\text { Negative } \\
\text { Atypical } \\
\text { Suspicious } \\
\text { Positive }\end{array}$ & $\begin{array}{c}18(9 \%) \\
7(4 \%) \\
6(3 \%) \\
159(84 \%)\end{array}$ & $\begin{array}{c}22(50 \%) \\
1(2 \%) \\
1(2 \%) \\
20(45 \%)\end{array}$ & $<0.0001$ & $\begin{array}{c}40(17 \%) \\
8(3 \%) \\
7(3 \%) \\
179(77 \%)\end{array}$ \\
\hline ROSE & $173(91 \%)$ & $32(73 \%)$ & 0.0009 & $205(88 \%)$ \\
\hline $\begin{array}{l}\text { Needle gauge } \\
19 \\
22 \\
25\end{array}$ & $\begin{array}{c}2(1 \%) \\
12(6 \%) \\
175(93 \%)\end{array}$ & $\begin{array}{c}0(0 \%) \\
2(5 \%) \\
42(95 \%)\end{array}$ & $>0.99$ & $\begin{array}{c}2(1 \%) \\
14(6 \%) \\
216(92 \%)\end{array}$ \\
\hline $\begin{array}{l}\text { Type of mass } \\
\text { Normal tissue } \\
\text { Chronic pancreatitis } \\
\text { Adenocarcinoma } \\
\text { NET } \\
\text { Lymphoma } \\
\text { Metastatic lesion } \\
\text { Other-GIST }\end{array}$ & $\begin{array}{c}16(8 \%) \\
0(0) \\
135(71 \%) \\
24(13 \%) \\
6(3 \%) \\
8(4 \%) \\
1(1 \%)\end{array}$ & $\begin{array}{c}0(0) \\
19(43 \%) \\
21(48 \%) \\
3(7 \%) \\
0(0) \\
1(2 \%) \\
0\end{array}$ & $<0.0001$ & $\begin{array}{c}16(7 \%) \\
19(8 \%) \\
156(67 \%) \\
27(12 \%) \\
6(3 \%) \\
9(4 \%) \\
1(1 \%)\end{array}$ \\
\hline
\end{tabular}

$\dagger$ lesions located on multiple parts of pancreas

EUS, endoscopic ultrasound; FNA, fine-needle aspiration; ROSE, rapid on-site evaluation by cytopathologist; NET, neuroendocrine tumor; GIST, gastrointestinal stromal tumor; N, number; SD, standard deviation; CBD, common bile duct; PD, pancreatic duct; US, ultrasound; CT, computed tomography; MRI, magnetic resonance imaging 
Table 3 Performance characteristics of EUS for suspected solid pancreatic lesions (pancreatic mass and/or biliary or pancreatic duct strictures) with or without chronic pancreatitis

\begin{tabular}{|c|c|c|c|c|}
\hline \multirow[t]{2}{*}{ Characteristics } & \multicolumn{2}{|c|}{ Chronic pancreatitis } & \multirow[t]{2}{*}{ P-value } & \multirow[t]{2}{*}{ Total $(\mathrm{N}=232)$} \\
\hline & No $(\mathrm{N}=188)$ & Yes $(\mathrm{N}=44)$ & & \\
\hline False negative & 9 & 5 & - & 14 \\
\hline False positive & 0 & 1 & - & 1 \\
\hline True negative & 16 & 18 & - & 34 \\
\hline True positive & 163 & 20 & - & 183 \\
\hline Sensitivity & $94.8(90.3,97.6)$ & $80.0(59.3,93.2)$ & 0.0199 & $92.9(88.4,96.1)$ \\
\hline Specificity & $100.0(79.4,100.0)$ & $94.7(74.0,99.9)$ & $>0.99$ & $97.1(85.1,99.9)$ \\
\hline PPV & $100.0(97.8,100.0)$ & $95.2(76.2,99.9)$ & 0.1141 & $99.5(97.0,100.0)$ \\
\hline NPV & $64.0(42.5,82.0)$ & $78.3(56.3,92.5)$ & 0.3493 & $70.8(55.9,83.1)$ \\
\hline Accuracy & $95.2(91.1,97.8)$ & $86.4(72.7,94.8)$ & 0.0429 & $93.5(89.6,96.3)$ \\
\hline
\end{tabular}

Factors that might be associated with the diagnostic accuracy of EUS-FNA were also analyzed. There were a total of 15 cases in the "misdiagnosis" group. This group included those with 14 cases of FN and 1 case with a FP interpretation. Among the FN cases, 8 of 14 (57.1\%) were confirmed by pathology after surgical resection and 6/14 (42.9\%) were diagnosed by clinical follow up, as determined by the progression of primary malignancy, demonstration of metastasis on subsequent imaging, or death related to malignancy. The FP case was confirmed to have $\mathrm{CP}$ on the basis of surgical pathology, while the FNA cytology report was suspicious for a NET. Additionally, 217 patients were seen in the "non-misdiagnosis" group with either 183 cases of true-positive or 34 cases of true-negative results. Compared to the "nonmisdiagnosis" group, the "misdiagnosis" group had a higher rate of underlying $\mathrm{CP}$ ( $40 \%$ vs. $18 \%, \mathrm{P}=0.043$ ) and a lower rate of onsite cytopathologist availability for rapid evaluation (67\% vs. $89 \%$, $\mathrm{P}=0.026$ ) (Table 4). ROSE demonstrated a higher sensitivity of EUS-FNA in patients with CP (90\% vs. $40 \%, \mathrm{P}=0.036)$ (Table 5).

\section{Predictive factors of $\mathrm{CP}$}

To predict the likelihood of underlying CP, 5 factors were recruited into a logistic model. These included age, sex, body mass index (BMI), abdominal pain and jaundice. Given the lack of BMI information in 7 cases, we included 227 cases in the multiple logistic regression model analysis. The model concluded that less than or equal to 60 years $(\mathrm{P}=0.011)$, low BMI $(\mathrm{P}=0.041)$, and absence of jaundice $(\mathrm{P}=0.022)$ were more likely to have CP (Table 6).

\section{Discussion}

In this retrospective study, EUS-FNA was found to have an overall sensitivity of $92.9 \%$, specificity of $97.1 \%$, and accuracy of $93.5 \%$ for the diagnosis of malignancy in patients with a finding of solid pancreatic lesions.

As described earlier, the presence of CP with lobulations, calcification and collateral vasculature may interfere with the visualization and evaluation of pertinent lesions, pose significant challenges to FNA due to the altered texture of the pancreas, and increase the risk of inadequate sampling or off-target biopsying [7]. Atypia in the pancreas has been seen in the form of reactive changes, cytologic preparation artifacts, CP, stent effects, contamination from the nondescript gastrointestinal epithelium (particularly ampullary epithelium), or well-differentiated ductal carcinoma and uncommon neoplasms [20]. In the setting of CP, sensitivity and accuracy were found to be significantly lower: $80.0 \%$ and $86.4 \%$, respectively. This is comparable to the available data in the published literature [2-6,9].

Rapid evaluation by an on-site cytopathologist has an important role in the EUS-FNA evaluation of pancreatic masses. Two recent meta-analyses evaluating EUS-FNA of pancreatic masses revealed that EUS-FNA has a higher sensitivity when an on-site cytopathologist is available, improving sensitivity from $80-81 \%$ to $88-95 \%$ [4,21]. We also noticed a similar trend, with a significantly higher proportion of patients with accurate FNA interpretation being labeled as the "non-misdiagnosis" group. We further sought to investigate whether the low diagnostic yield in the setting of CP could be effected by ROSE. Our results indicated that ROSE demonstrated a higher sensitivity of EUS-FNA in patients with CP ( $90 \%$ vs. $40 \%, \mathrm{P}=0.036$ ). Therefore, we consider ROSE to be an important factor in improving the diagnostic accuracy of EUS-FNA in patients with underlying CP.

We also found that patients with age less than or equal to 60 years, low BMI, and the absence of jaundice were more likely to have underlying CP. As expected, almost half (23/44) of the patients with CP had an associated pancreatic solid mass lesion. As described earlier, $\mathrm{CP}$ and pancreatic cancer share common risk factors. However, this information could be 
Table 4 Comparison of clinical, radiological, endosonographic and cytological features in "misdiagnosis" (FN+FP) and "non-misdiagnosis" (TN+TP) groups

\begin{tabular}{|c|c|c|c|}
\hline \multirow[t]{3}{*}{ Characteristics } & \multicolumn{2}{|c|}{ EUS-FNA $(\mathrm{N}=232)$} & \multirow[t]{3}{*}{ P-value } \\
\hline & $\mathrm{FN}+\mathrm{FP}(\mathrm{N}=15)$ & $\mathrm{TN}+\mathrm{TP}(\mathrm{N}=217)$ & \\
\hline & $\mathrm{N}(\%)$ or mean $\pm \mathrm{SD}$ & $\mathrm{N}(\%)$ or mean $\pm \mathrm{SD}$ & \\
\hline Age (years) & $64.7 \pm 13.40$ & $67.9( \pm 12.57)$ & 0.3363 \\
\hline $\begin{array}{l}\text { Sex } \\
\text { Female } \\
\text { Male }\end{array}$ & $\begin{array}{l}8(53 \%) \\
7(47 \%)\end{array}$ & $\begin{array}{c}84(39 \%) \\
133(61 \%)\end{array}$ & 0.2628 \\
\hline BMI $\left(\mathrm{kg} / \mathrm{m}^{2}\right)$ & $28.4( \pm 4.31)$ & $27.6 \pm 6.27$ & 0.6466 \\
\hline Abdominal pain & $11(73 \%)$ & $149(69 \%)$ & $>0.99$ \\
\hline Jaundice & $6(40 \%)$ & $93(43 \%)$ & 0.8287 \\
\hline Chronic pancreatitis & $6(40 \%)$ & $38(18 \%)$ & 0.0429 \\
\hline Mean diameter of lesions (cross-imaging) ( $\mathrm{mm}$ ) & $41.1 \pm 31.92$ & $32.3 \pm 16.73$ & 0.3067 \\
\hline $\begin{array}{l}\text { Location of lesions (EUS) } \\
\text { None } \\
\text { Head/neck } \\
\text { Body } \\
\text { Tail } \\
\text { Others } \dagger\end{array}$ & $\begin{array}{c}0(0 \%) \\
7(47 \%) \\
3(20 \%) \\
4(27 \%) \\
1(7 \%)\end{array}$ & $\begin{array}{c}18(8 \%) \\
119(55 \%) \\
32(15 \%) \\
32(15 \%) \\
16(7 \%)\end{array}$ & 0.5325 \\
\hline $\begin{array}{l}\text { FNA cytology } \\
\text { Negative } \\
\text { Atypical } \\
\text { Suspicious } \\
\text { Positive }\end{array}$ & $\begin{array}{c}7(47 \%) \\
7(47 \%) \\
1(7 \%) \\
0(0)\end{array}$ & $\begin{array}{c}33(15 \%) \\
1(0) \\
6(3 \%) \\
177(82 \%)\end{array}$ & $<0.0001$ \\
\hline ROSE & $10(67 \%)$ & $193(89 \%)$ & 0.0264 \\
\hline $\begin{array}{l}\text { Needle gauge } \\
19 \\
22 \\
25\end{array}$ & $\begin{array}{c}0(0) \\
2(13 \%) \\
13(87 \%)\end{array}$ & $\begin{array}{c}2(1) \\
12(6 \%) \\
202(93 \%)\end{array}$ & 0.3728 \\
\hline $\begin{array}{l}\text { Type of mass } \\
\text { Normal tissue } \\
\text { Chronic pancreatitis } \\
\text { Adenocarcinoma } \\
\text { NET } \\
\text { Lymphoma } \\
\text { Metastatic lesion } \\
\text { Other-GIST }\end{array}$ & $\begin{array}{c}0(0) \\
1(7 \%) \\
7(47 \%) \\
3(20 \%) \\
0(0) \\
3(20 \%) \\
1(1 \%)\end{array}$ & $\begin{array}{c}16(7 \%) \\
18(8 \%) \\
149(69 \%) \\
24(11 \%) \\
5(2 \%) \\
5(2 \%) \\
0\end{array}$ & 0.0047 \\
\hline
\end{tabular}

g: 2 of 234 cases posed a diagnostic dilemma and has been excluded, and therefore only 232 cases included

$\dagger$ lesions located on multiple parts of the pancreas

EUS, endoscopic ultrasound; FN, false negative; FP, false positive; TN, true negative; TP, true positive; BMI, body mass index; ROSE, rapid on-site evaluation by cytopathologist; NET, neuroendocrine tumor; GIST, gastrointestinal stromal tumor; $N$, number; SD, standard deviation

beneficial. For instance, negative cytology for malignancy in a younger patient ( $<60$ years), with a low BMI and no jaundice, yet with underlying CP on EUS, can be somewhat reassuring. This is certainly of value in setting the pre-test probability in these challenging cases. Clinical follow up in this subset of patients is key to ensuring that potentially FN cases do not go unnoticed for an extended period of time.

As expected, a subgroup of patients with $\mathrm{CP}$ and pancreatic neoplasms may have biliary stents in place, raising the possibility of atypia from causes other than a neoplastic process. This could potentially result in the need for repeat FNA passes. Significantly more FNA passes were needed in the $\mathrm{CP}$ group compared to the non-CP group. Varadarajulu et al revealed that patients with CP required more EUS-FNA passes to establish a diagnosis compared to those without CP, with a median of 5 vs. 2, respectively [10]. LeBlanc et al revealed that EUS-FNA examinations with 7 passes into pancreatic lesions had higher sensitivity compared to those with 5 passes: $83 \%$ vs. $77 \%$, respectively [22]. In the event EUS-FNA depicts negative or atypical cytology, yet the clinical suspicion for an underlying malignancy is high, more passes should be performed at the direction of the cytopathologist before malignancy can be reliably excluded. 
Table 5 Performance characteristics of endoscopic ultrasoundguided fine-needle aspiration in the setting of chronic pancreatitis

\begin{tabular}{lccc}
\hline \multirow{2}{*}{ Characteristics } & \multicolumn{2}{c}{ ROSE } & P-value \\
\cline { 2 - 3 } & No $(\mathrm{N}=12)$ & Yes $(\mathrm{N}=32)$ & \\
\hline Sensitivity & 40.0 & 90.0 & 0.0358 \\
& $(5.3,85.3)$ & $(68.3,98.8)$ & \\
Specificity & 100.0 & 91.7 & $>0.99$ \\
& $(59.0 .100 .0)$ & $(61.5,99.8)$ & \\
Accuracy & 75.0 & 90.6 & 0.3215 \\
& $(43.8,94.5)$ & $(75.0,98.0)$ & \\
\hline
\end{tabular}

ROSE, rapid on-site evaluation by cytopathologist; $N$, number; $S D$, standard deviation

Table 6 Clinical predictors of chronic pancreatitis in patients undergoing EUS-FNA for suspected solid pancreatic lesions (pancreatic mass and/or biliary or pancreatic duct strictures)

\begin{tabular}{lcc}
\hline $\mathrm{N}=227 \neq$ Predicting factors & Adjusted OR $(95 \% \mathrm{CI})$ & P-value \\
\hline Age $\leq 60$ vs. $>60$ & $2.6(1.25,5.37)$ & 0.0108 \\
Gender: Male vs. Female & $1.8(0.87,3.91)$ & 0.1083 \\
BMI $\left(\mathrm{kg} / \mathrm{m}^{2}\right)$ & $0.94(0.879,0.997)$ & 0.0412 \\
Abdominal pain: Yes vs. No & $1.2(0.55,2.61)$ & 0.6406 \\
Jaundice: Yes vs. No & $0.41(0.189,0.877)$ & 0.0218 \\
\hline
\end{tabular}

¥: 7 of 234 cases missing BMI data, and only 227 cases included for predicting factors logistic regression analysis

BMI, body mass index; $N$, number; OR, odds ratio; CI, confidence interval

Various gauge sizes of EUS-FNA needles are available for performing FNA in the pancreas, notably 25-, 22- and 19-G needles. 25-G needles, in comparison to $22-$ and $19-\mathrm{G}$ needles, are easier to handle, penetrate more easily, are less likely to yield samples contaminated with blood, and cause fewer complications [2,23-26]. Interestingly, a recent meta-analysis indicated that 25-G FNA needles are not inferior to 22-G FNA needles in diagnostic yield in solid pancreatic lesions, and that 25-G FNA needles have higher sensitivity but comparable specificity to $22-\mathrm{G}$ needles (pooled sensitivity: $93 \%$ vs. $85 \%$, pooled specificity: $97 \%$ vs. $100 \%$ ) [27]. Cancer cells are often trapped in the setting of severe $\mathrm{CP}$, because of the desmoplastic stroma, and often yield only a scant aspirate or dry tap [7]; in that case, suction may be used, or core biopsy may be considered. However, routine utilization of suction or stylet is not supported by current evidence, as they tend to increase the likelihood of blood contamination of the specimen $[7,28]$.

The main limitation of this study is inherent to the retrospective design. The other limitation is related to the interpretation of $\mathrm{CP}$, which in turn is also related to the retrospective design. Although we employed the Rosemont criteria to make a diagnosis of $\mathrm{CP}$, we also took into consideration operators' overall impression. Since data were not collected prospectively, all features relative to $\mathrm{CP}$ were not always available on retrospective chart review.

This study is unique, however, in that it is presented from a high-volume community-based nonacademic referral center with the availability of on-site cytopathologists. This is important to note because referral bias regarding established academic practices could affect the index of clinical suspicion in these challenging cases. However, most of the patients referred to this center were seeking first-time evaluation for this issue. These data will help a broader spectrum of community-based practice endoscopists determine cost-effective strategies for EUS-FNA evaluation of solid pancreatic masses.

In conclusion, the diagnostic sensitivity and accuracy of EUS-FNA for solid pancreatic masses are significantly lower in the setting of CP. A high index of clinical suspicion is required in these cases to make a definitive diagnosis.

\section{Summary Box}

\section{What is already known:}

- Endoscopic ultrasound-guided fine-needle aspiration (EUS-FNA) is routinely employed in evaluating patients with suspected pancreatic malignancy

- Patients with pancreatic malignancies and chronic pancreatitis (CP) share similar clinical presentation and risk factors, and the conditions often coexist

- CP decreases the yield of EUS-FNA in patients with pancreatic malignancy

\section{What the new findings are:}

- Overall, EUS-FNA is an excellent tool in evaluating patients with pancreatic malignancy, with an overall sensitivity of $92.9 \%$, specificity of $97.1 \%$, and accuracy of $93.5 \%$

- The diagnostic accuracy of EUS-FNA in detecting solid pancreatic lesions is significantly effected by the presence of $\mathrm{CP}$

- The availability of on-site cytopathologist evaluation can improve the diagnostic yield of EUS-FNA in patients with CP

\section{References}

1. Kulesza P, Eltoum IA. Endoscopic ultrasound-guided fine-needle aspiration: sampling, pitfalls, and quality management. Clin Gastroenterol Hepatol 2007;5:1248-1254.

2. Kamata K, Kitano M, Omoto S, et al. New endoscopic ultrasonography techniques for pancreaticobiliary diseases. Ultrasonography 2016;35:169-179.

3. Chen G, Liu S, Zhao Y, Dai M, Zhang T. Diagnostic accuracy of endoscopic ultrasound-guided fine-needle aspiration for pancreatic cancer: a meta-analysis. Pancreatology 2013;13:298-304.

4. Hewitt MJ, McPhail MJ, Possamai L, Dhar A, Vlavianos P, Monahan KJ. EUS-guided FNA for diagnosis of solid pancreatic neoplasms: a meta-analysis. Gastrointest Endosc 2012;75:319-331.

5. Itoi T, Sofuni A, Itokawa F, Irisawa A, Khor CJ, Rerknimitr R. Current 
status of diagnostic endoscopic ultrasonography in the evaluation of pancreatic mass lesions. Dig Endosc 2011;23(Suppl 1):17-21.

6. Puli SR, Bechtold ML, Buxbaum JL, Eloubeidi MA. How good is endoscopic ultrasound-guided fine-needle aspiration in diagnosing the correct etiology for a solid pancreatic mass?: A meta-analysis and systematic review. Pancreas 2013;42:20-26.

7. Bang JY, Varadarajulu S. Neoplasia in chronic pancreatitis: how to maximize the yield of endoscopic ultrasound-guided fine needle aspiration. Clin Endosc 2014;47:420-424.

8. Fritscher-Ravens A, Topalidis T, Bobrowski C, et al. Endoscopic ultrasound-guided fine-needle aspiration in focal pancreatic lesions: a prospective intraindividual comparison of two needle assemblies. Endoscopy 2001;33:484-490.

9. Krishna NB, Mehra M, Reddy AV, Agarwal B. EUS/EUS-FNA for suspected pancreatic cancer: influence of chronic pancreatitis and clinical presentation with or without obstructive jaundice on performance characteristics. Gastrointest Endosc 2009;70:70-79.

10. Varadarajulu S, Tamhane A, Eloubeidi MA. Yield of EUS-guided FNA of pancreatic masses in the presence or the absence of chronic pancreatitis. Gastrointest Endosc 2005;62:728-736.

11. Eloubeidi MA, Chen VK, Eltoum IA, et al. Endoscopic ultrasoundguided fine needle aspiration biopsy of patients with suspected pancreatic cancer: diagnostic accuracy and acute and 30-day complications. Am J Gastroenterol 2003;98:2663-2668.

12. Harewood GC, Wiersema MJ. Endosonography-guided fine needle aspiration biopsy in the evaluation of pancreatic masses. Am J Gastroenterol 2002;97:1386-1391.

13. Williams DB, Sahai AV, Aabakken L, et al. Endoscopic ultrasound guided fine needle aspiration biopsy: a large single centre experience. Gut 1999;44:720-726.

14. Gleeson FC, Kipp BR, Caudill JL, et al. False positive endoscopic ultrasound fine needle aspiration cytology: incidence and risk factors. Gut 2010;59:586-593.

15. Gardner TB, Taylor DJ, Gordon SR. Reported findings on endoscopic ultrasound examinations for chronic pancreatitis: toward establishing an endoscopic ultrasound quality benchmark. Pancreas 2014;43:37-40.

16. Catalano MF, Sahai A, Levy M, et al. EUS-based criteria for the diagnosis of chronic pancreatitis: the Rosemont classification. Gastrointest Endosc 2009;69:1251-1261.

17. Lieb JG $2^{\text {nd }}$, Palma DT, Garvan CW, et al. Intraobserver agreement among endosonographers for endoscopic ultrasound features of chronic pancreatitis: a blinded multicenter study. Pancreas 2011;40:177-180.
18. Stevens T, Lopez R, Adler DG, et al. Multicenter comparison of the interobserver agreement of standard EUS scoring and Rosemont classification scoring for diagnosis of chronic pancreatitis. Gastrointest Endosc 2010;71:519-526.

19. Duggan SN, Ní Chonchubhair HM, Lawal O, O'Connor DB, Conlon KC. Chronic pancreatitis: A diagnostic dilemma. World J Gastroenterol 2016;22:2304-2313.

20. Abdelgawwad MS, Alston E, Eltoum IA. The frequency and cancer risk associated with the atypical cytologic diagnostic category in endoscopic ultrasound-guided fine-needle aspiration specimens of solid pancreatic lesions: a meta-analysis and argument for a Bethesda System for Reporting Cytopathology of the Pancreas. Cancer Cytopathol 2013;121:620-628.

21. Hébert-Magee S, Bae S, Varadarajulu S, et al. The presence of a cytopathologist increases the diagnostic accuracy of endoscopic ultrasound-guided fine needle aspiration cytology for pancreatic adenocarcinoma: a meta-analysis. Cytopathology 2013;24:159-171.

22. LeBlanc JK, Ciaccia D, Al-Assi MT, et al. Optimal number of EUSguided fine needle passes needed to obtain a correct diagnosis. Gastrointest Endosc 2004;59:475-481.

23. Lee JH, Stewart J, Ross WA, Anandasabapathy S, Xiao L, Staerkel G. Blinded prospective comparison of the performance of 22-gauge and 25-gauge needles in endoscopic ultrasound-guided fine needle aspiration of the pancreas and peri-pancreatic lesions. Dig Dis Sci 2009;54:2274-2281.

24. Rastogi A, Wani S, Gupta N, et al. A prospective, single-blind, randomized, controlled trial of EUS-guided FNA with and without a stylet. Gastrointest Endosc 2011;74:58-64.

25. Siddiqui UD, Rossi F, Rosenthal LS, Padda MS, Murali-Dharan V, Aslanian HR. EUS-guided FNA of solid pancreatic masses: a prospective, randomized trial comparing 22-gauge and 25-gauge needles. Gastrointest Endosc 2009;70:1093-1097.

26. Yusuf TE, Ho S, Pavey DA, Michael H, Gress FG. Retrospective analysis of the utility of endoscopic ultrasound-guided fine-needle aspiration (EUS-FNA) in pancreatic masses, using a 22-gauge or 25-gauge needle system: a multicenter experience. Endoscopy 2009;41:445-448.

27. Madhoun MF, Wani SB, Rastogi A, et al. The diagnostic accuracy of 22-gauge and 25-gauge needles in endoscopic ultrasound-guided fine needle aspiration of solid pancreatic lesions: a meta-analysis. Endoscopy 2013;45:86-92.

28. Varadarajulu S, Fockens P, Hawes RH. Best practices in endoscopic ultrasound-guided fine-needle aspiration. Clin Gastroenterol Hepatol 2012;10:697-703. 